\title{
ИЗУЧЕНИЕ ЗНАЧЕНИЙ КИТАЙСКИХ И РУССКИХ ИДИОМ С ТОЧКИ ЗРЕНИЯ ПЕРЕВОДА
}

\section{STUDYING THE MEANINGS OF CHINESE AND RUSSIAN IDIOMS FROM THE POINT OF TRANSLATION}

\section{Liu Chang}

Summary: Objective: To review and study the origins and cultural differences of idioms reflected in Chinese and Russian in terms of translation.

Methods: In this article, it is very important to compare, analyze and study the cultural and historical difference between idioms in Russian and Chinese languages, as well as understand their differences between themselves.

Results: This article examines the cultural and historical meanings in Russian and Chinese idioms and examines separately each aspect of translation in two different cultures.

Conclusions: The main conclusion of this article is that for a better understanding of the meanings of idioms in Russian and Chinese in two different cultures, one must first find their exact meaning, translate them correctly, and then compare them with each other to see the cultural contrast.

Keywords: translation, Chinese idioms, Russian idioms, comparative research.

\author{
Лю Чан \\ аспирант, Российский университет дружбы народов, \\ Москва \\ 3289659550@q9.com
}

Аннотация: Цель: Рассмотреть и изучить происхождения и культурные различия идиом, отраженные в китайском и русском языках с точки зрения перевода.

Методы: В данной статье очень важно сравнить, проанализировать и изучить культурную и историческую разницу идиом в русском и китайском языках, а также понять их различия между собой.

Результаты: В данной статье рассматриваются культурные и исторические значения в русских и китайских идиомах и отдельно изучается каждый аспект перевода в двух разных культурах.

Выводы: Основным выводом данной статьи является то, что для лучшего понимания значений идиом в русском и китайском языках в двух разных культурах нужно сначала найти их точное значение, правильно перевести, а дальше сопоставить их между собой, чтобы увидеть культурный контраст.

Ключевые слова: перевод, китайские идиомы, русские идиомы, сравнительное исследование.
Я зык - одно из важнейших средств межкультурного общения, и языки каждой нации содержат разные виды идиом. Френсис Бэкон однажды сказал, что «Идиомы могут олицетворять творческие способности, мудрость и дух нации» (Фрэнсис Бэкон сказал: «Гений, ум и дух нации раскрываются в их идиомах»). Отсюда видно, что идиомы играют важную роль для национальной культуры, а именно ознакомится с самой нацией и выучить их язык.

Идиомы относятся к часто используемым фиксированным фразам, которые представляют собой фиксированные комбинации слов с тесной семантической интеграцией и являются лексическими единицами, используемыми в языке независимо. Идиомы обычно имеют две характеристики: стабильность структуры и целостность значения.

«В словарном запасе, помимо множества независимо используемых слов, есть также несколько готовых фраз, которые часто используются обычными людьми, а также стали строительным материалом языка и составной частью словарного запаса - они носят общее название
«Идиомы». Идиомы включают в себя устойчивые выражения, пословицы, недоговорки, народные выражения, афоризмы и т.д.» [1]

Различные нации имеют свои собственные различия в идиомах из-за географического положения, исторического развития, религиозных убеждений, культурных обычаев и жизненных привычек. Идиомы в значительной степени несут в себе характеристики различных национальных культур и языков, идиомы тесно связаны с традиционной культурой и историческим развитием каждого народа, то есть неразделимы.

Идиомы - это зеркало национального языка, отражающее историческое и культурное происхождение, ценности и образ мышления нации. При использовании языков разных национальностей неизбежно использование идиом, уникальных для каждой национальности, в связи с этим языковой перевод идиом стал серьезной проблемой. В то же время хорошее применение идиом разных национальностей может лучше показать различные характеристики этой национальности, что является одной из уникальных задач перевода идиом. 
Существуют различия в способах языкового выражения, логическом мышлении и грамматическом строении разных национальностей. Например, русский язык принадлежит к индоевропейской языковой семье, а большинство языков индоевропейской языковой семьи являются флективными языками, которые широко используют аффиксы и коренные изменения гласных для выражения грамматического значения: существительные и большинство прилагательных претерпели изменения, например, в падеже, роде и числе; глаголы меняются по времени, голосу и стилю; подлежащее и глагол перекликаются друг с другом в этом изменении. Кроме того, в словах индоевропейских языков есть ударения.

Китайский язык - это одна из важных частей сино-тибетских языков в китайско-тибетской языковой семье. Фиксированный тон каждого слога - значимая особенность языка китайско-тибетских языков. По тонам можно различать значение слов. В языках сино-тибетской языковой семьи порядок слов и служебные слова используются как важные средства для выражения грамматического значения. Порядок слов относительно фиксированный. Есть много типов служебных слов, которые выражают различные грамматические значения в предложениях. Одна из характеристик частей речи китайско-тибетских языков - наличие кванторов. Роль кванторов в основном выражает единицу вещей и количество действий. Кроме того, квантификаторы на многих языках также выражают характеристики категории, формы, пола и уровня вещей. В языках сино-тибетской языковой семьи есть перекрывающиеся формы слов, которые имеют общие характеристики во многих языках, представляющие объем, функцию и форму перекрытия. Во-вторых, в каждом языке также есть набор вспомогательных слов, которые выражают различные модели предложений и настроения, которые обычно используются в конце предложений. [2]

Только при сравнении языковых семей, русский и китайский языки сильно отличаются друг от друга. Как мы уже говорили, историческое развитие, географическое положение и другие факторы делают разницу между русским и китайским двуязычием более очевидной. Можно сказать, что это два совершенно разных языка.

В то же время Россия - западная страна, и ее язык обладает характеристиками логического и абстрактного мышления, к которым привыкли западные страны. А китайцы больше внимания уделяют мышлению образами. Таким образом, культурные различия, отраженные в русских и китайских идиомах, можно выразить в следующих аспектах:

\section{А. Различия в географическом положении}

Происхождение идиом тесно связано со средой обитания людей, они также могут отражать внешние условия человеческого существования, такие как экологическая среда и климатическая среда. Например, в китайском языке есть следующая идиома «橘生淮南(jú shēng huáinán)». Эта идиома означает букв. мандарин, уродившись на юге, называется мандарином, уродившись на севере, называется горьким апельсином обр. характеристики вещей меняются вместе с изменением окружающей среды; бытие определяет сознание, среда формирует человека.

Россия - северная страна. Большая часть страны расположена в северной умеренной зоне. Зима долгая и холодная. Многие районы покрыты снегом и льдом круглый год. Белый цвет стал основным цветом русской зимы. Поэтому в России существует такая русская фраза, как белая зима (середина зимы).

Китай расположен на азиатском континенте и имеет давнюю культуру земледелия, поэтому в китайском языке существует множество идиом, связанных с землей и сельским хозяйством. Например: идиома «Какие вода и земля, таких и людей они родят» что означает, люди, с одинаковым происхождением, имеют много общего. Изза разной окружающей среды, разных способов жизни и разного географического климата возникают разные идеологические концепции и культурные особенности.

\section{Б. Различия в религиозных верованиях}

Буддизм - одна из пяти основных религий Китая. Буддизм появился в Китае во время династии Хань. Эта религия имеет почти 2000-летнюю историю и широко распространена в Китае, в связи с этим многие китайские идиомы связаны с буддизмом. Например: «Не смотри в лицо монаха, чтобы увидеть лицо Будды» (из китайского романа «Путешествие на Запад»). «Not for the sake of the monk but for that of the Buddha» в переводе на русский язык «Не ради монаха, а ради Будды», как метафора означает «цените чувства человека с третьей стороны, чтобы помочь ему и помиловать». В России большинство людей верят в православие, например: выражение «Я умываю руки» пришло к нам из Библии.

\section{В. Различия в исторических ам^юзиях}

Большинство идиом в китайском языке происходят из исторических аллюзий и взяты из различных исторических книг. В таких идиомах часто используются простые слова, но их значение очень далеко идущее, и многие не могут быть просто переведены из значения самого словаря. Чтобы понять значение идиомы, необходимо понять историю, когда идиома была сформирована, и социальное происхождение в то время, чтобы понять коннотацию идиомы. Многие идиомы буквально абсурдны и бессмысленны. Например: идиома «В тексте точки не добавляются». Если рассматривать эту идиому из буквального значения, то легко понять, что статьи пи- 
шут без знаков препинания. Но когда мы поймем источник этой идиомы, то это значит, написание статьи может быть выполнено за один раз без изменений. Но с точки зрения этой идиомы, ее на самом деле трудно понять, поэтому мы можем взглянуть на источник этой идиомы. Идиома «В тексте точки не добавляются» произошла в династии Нань Лян, она взята из «Предисловия к попугаю Фу» Сяо Тун: «Хэн держа перо,не останавливаеися ни перед чем. В тексте точки не добавляются» [3]. Это означает, что есть человек по имени Хэн, который быстро думает и пишет статьи, не задумываясь, может очень хорошо делать свою работу. Следовательно, иностранцам, чтобы изучать китайские идиомы, лучше всего просто понять источник этих идиом, чтобы они могли лучше запоминать и понимать китайские идиомы, и в то же время они могли лучше понимать китайскую культуру и историю. Большая часть русских идиом происходит из «Библии». Чтобы понять эти идиомы, вам также необходимо понять содержание «Библии».

Исходя из этого, мы можем сказать, что изучение идиом любой страны неотделимо от ее исторического развития и культурных коннотаций. Только когда вы полностью поймете это содержание, вы сможете легко и без слов переводить их на соответствующий язык, правильно выражая смысл. С другой стороны, это также показывает, что изучение идиом может помочь лучше понять культуру других стран.

Итак, как два языка столкнулись с огромными различиями в преодолении этих трудностей при переводе? Как мы уже говорили выше, как переводчику, вам нужно не только научиться понимать язык и символы страны, но и необходимо для глубоко понять уникальность особенностей культуры страны, ее исторического развития, этнических привычек и т. д. Только когда вы полностью ознакомитесь и изучите страну, вы сможете преобразовать язык одной страны в язык, другой страны и донести правильный смысл людям при переводе. Поэтому при переводе, особенно когда вы сталкиваетесь с идиомами, вы можете использовать подход «трансформации».

Когда мы сталкиваемся с идиомами, мы должны сначала понять значение, выражаемое идиомой. Если буквальное значение не совпадает с глубоким значением, тогда нам необходимо преобразовать его. Это преобразование может быть простым преобразованием идиомы в ее глубокий смысл. Например, «Разве вы не смотрите свысока на маленькой девочку как на ломкую иву?». Идиому «Пу Лю Чжи Цзы», в этом предложении можно легко понять буквально как покачивающуюся как иву, изящную позу, так что это совершенно неверно. Согласно неправильному пониманию, это предложение становится «Разве ты не смотришь свысока на красивую позу маленькой девочки?», но на самом деле «Пу Лючжи» описывает человека со слабым телом и посредственными способностями. Обычно эта идиома, которая исполь- зуется, чтобы быть скромным, а не хвастливым. На самом деле, смысл этого предложения должен быть таким: «Вам не кажется, что девушка посредственная, поэтому вы смотрите на девушку свысока?».

Столкнувшись с такими идиомами, буквальное и действительное значения которых не совпадают, нам необходимо их преобразовать. Идиомы можно правильно использовать только путем преобразования простых буквальных значений в более глубокие значения.

Другой метод преобразования - преобразование идиом в идиомы с тем же значением на соответствующем языке. Это также может сделать переведенный контент более индивидуальным и более подходящим для перевода. Например, самая распространенная пословица «Все дороги ведут в Рим» имеет одну и ту же идиому в русском языке: «Всякие дороги ведут к Риму». В русском или китайском языках эти две идиомы имеют одинаковое значение. Точно так же, когда мы сталкиваемся с этой ситуацией, мы можем напрямую преобразовать один язык в другой, не внося слишком много изменений. Конечно, такая трансформация основана на понимании переводчиком языков и культур двух стран, и это довольно сложно.

Согласно соответствующей степени, преобразование также можно разделить на три типа, проиллюстрируем их примерами.

Первый тип полностью соответствует конверсии:

Время-деньги (на рус.яз.) = 时间就是金钱 (время деньги на кит.яз.);

Как рыба в воде = 如鱼得水 (как рыба в воде на кит.яз.).

Видно, что такое полное преобразование соответствия относится к тому, что идиома абсолютно одинакова на двух языках, будь то буквальное выражение или глубокое значение, это одно и то же. В этом случае при переводе используется только одна идиома. слова одной страны можно напрямую перевести на идиомы другой страны без объяснения его глубокого смысла.

Второй тип - полусоответствующая трансформация:

На языке мед, а под языком лед = 笑里藏刀, что означает за улыбкой прятать нож;

Не видеть дальше своего носа = 鼠目寸光, а переводе с китайского на русский язык означает "Глаза мыши видят не дальше одного цуня" (обр. в знач.: ограниченный).

Полусоответствующее преобразование означает, что значение идиомы одно и то же, но риторика другая, стилистическая фигура может быть другой. В вышеприведенном нами примере на китайском означает, что в улыбке спрятан нож, который описывает внешность любезности по отношению к людям, но на самом деле это означает зловещий и хитрый. В китайском языке исполь- 
зуются изображения «улыбка» и «нож», в русских идиомах, выражающие это значение: «язык», «мед», «лед». Некоторые из этих полусоответствующих преобразований имеют схожие значения, но при использовании в разных ситуациях и контекстах некоторые имеют похожие буквальные значения, но имеют совершенно разные коннотации. В конце концов, китайско-русские идиомы - это языки, которые используются в разных культурных традициях. Во многих случаях они могут лишь частично передавать сходные культурные особенности и не полностью согласованы. Поэтому при их переводе необходимо гибко трансформировать и соответствующим образом выбирать метод трансформации для того, чтобы сделать перевод более точным. Полусоответствующее преобразование на самом деле должно быть относительно продвинутым методом перевода, потому что многие идиомы подвержены влиянию культуры, и при переводе невозможно сохранить буквальное и образное значения. Этот вид полусоответствующего преобразования преобразует в идиомы соответствующих стран. Знакомые идиомы, передающие семантику исходного текста, трудны для переводчиков, но они очень практичны и эффективны.

Последний тип - несоответствующее преобразование: некоторые идиомы имеют более или менее сходства по поверхностной форме или значению, но фактическое значение совершенно иное. В этой ситуации переводчики могут усердно работать над переводом совершенно разных идиом в простые переводы практического значения или могут найти альтернативные соответствующие идиомы для замены.

В преобразовании перевода есть также несколько советов по переводу:

\section{А. Аббревиатура}

Содержание некоторых идиом содержит чрезвычайно сильные национальные характеристики, которые не могут быть переведены на другой язык, или когда для объяснения таких характеристик требуется большой объем, можно не затрагивая основное содержание, вы- брать соответствующую аббревиатуру. Например, русская идиома «В чужой монастырь со своим уставом не ходят» для ее выражения можно напрямую использовать китайскую идиому, а именно: «Делайте, как местные жители». Фраза «Со своим уставом» в русской идиоме опускается непосредственно в процессе перевода, чтобы она не влияла на выражение содержания и была легкой для понимания.

\section{Б. Аобавления}

Поскольку между разными культурами существует много различий, культурные слова во многих странах не имеют соответствующего словарного запаса в другой стране, что приводит к возникновению пробелов в значении слов. В такой ситуации, чтобы сохранить национальные особенности и образ исходного текста, в процессе перевода часто необходимо применять дополнительные методы, то есть дословный перевод и добавление подсказок для восполнения таких пробелов. Эти советы обычно можно использовать в качестве дополнения к справочным материалам, источникам словарного запаса и другой связанной информации для облегчения понимания. Например, в русском языке много идиом из Библии, и эта часть содержания как раз та часть, которую не понимает большинство китайцев. Поэтому при переводе можно добавить предложение к объяснению определенного содержания. Таким образом, люди смогут легко понять объяснения из «Библии» на другом языке.

\section{Зак^ючение}

Идиомы - это языковой феномен, который объединяет человеческую мудрость и занимает свое уникальное место в долгой истории развития и социальной практики. Значение изучения идиом заключается не только в понимании различных выражений языка. В то же время, изучая идиомы, можно лучше применять язык в межкультурном общении, изучать процесс развития страны и понимать человеческую историю языковой эволюции. Из этого следует, что изучение идиом имеет большое значение.

\section{ЛИТЕРАТУРА}

1. Ху Юйшу «Современный китайский язык», Шанхайское образовательное издание, 1981, 28 стр.

2. https://baike.baidu.com/item/\%E6\%B1\%89\%E8\%97\%8F\%E8\%AF\%AD\%E7\%B3\%BB/364341

3. https://baike.baidu.com/reference/2510113/fc4d74063zYEMgPRC7Vh1Vcvp3n4wsN-ewhltThunUWgqzaTbyHenmGnyvxGLWmQdSbI5pkIfwScaBjAsscNWBUCVZG VZGVZGVZGVZGVZGVZGU

4. Ц Цзя Шуфэнь, «Краткий словарь русских и китайских пословиц [М]». Шэньян: Издание Ляониньского университета, 1996.

5. Ван Фусянь, У Ханьин, «Литература языка и культуры [М]», Пекин: Издательство по изучению иностранных языков и исследований, 1994.

6. Ху Вэньчжун, «Культура и коммуникация [М]». Пекин: Издательство по изучению иностранных языков и исследований, 1998 г.

(С) Лю Чан (3289659550@qq.com). 